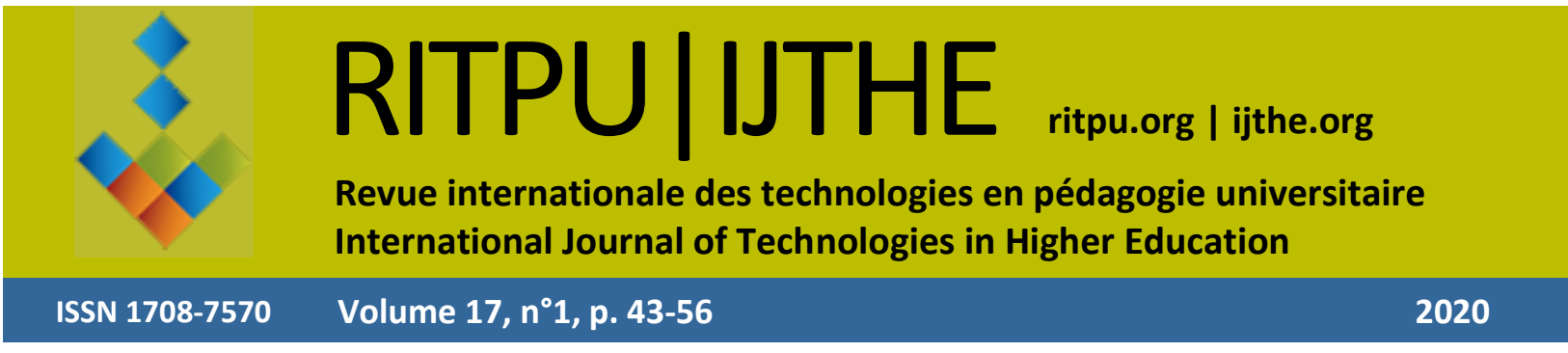

\title{
Physics, Smartphones and 3D-Print Technology: A Digital-Transition Case Study in Science Education
}

Chris Isaac LARNDER chrisisaac.larnder@johnabbott.qc.ca

John Abbott College

https://doi.org/10.18162/ritpu-2020-v17n1-10

Faïza NEBIA

FNEBIA@cvm.qc.ca

Cégep du Vieux Montréal

Margaret LIVINGSTONE m.livingstone@marianopolis.edu

Marianopolis College

Shiwei HUANG

shiwei.huang@johnabbott.qc.ca

John Abbott College

\begin{abstract}
We describe the stages of technological development in a 4-year project designed to adapt college-level physics education to the realities of the digital era. The project is a case study that draws on a wide range of complementary innovations to provide a better overall understanding of how technological transitions take place in an educational setting and, in particular, in the education of students in science and engineering fields.

The complete lifecycle of technological-change projects is examined. Various longer-term challenges are evaluated, including the development of new skills in teachers and support staff and the need for investments in equipment in participating educational institutions. Québec's recent Digital Action Plan is used both as a reference funding framework for discussion and as an example of how individual technology-based projects can indirectly benefit from broader government investments that target the college network as a whole.
\end{abstract}

\section{Keywords}

Digital technology, teaching, teacher training, teacher development, professional growth 


\section{Introduction}

\section{Science Education in a Digital Landscape}

Today's students are increasingly immersed in a digital landscape. Their primary source of experience is now mediated through mobile screens and laptop monitors instead of direct interactions with the physical world (Alvermann, 2004; Morley, 2001). This new reality has important implications for science pedagogy in general and physics education in particular (Crompton et al., 2016; Strimel \& Grubbs, 2016; Tang \& Tsai, 2016; Weintrop et al., 2016).

A cornerstone of science education is the establishment of links between general theories and the application of those theories to specific phenomena in the everyday world. To ensure that science students continue to be engaged, educators must renew their repertoire of classical examples with digital-era ones that are more relevant to the new world in which students now live.

For today's students, the everyday world of physics is no longer the experience of sliding down a ramp or throwing a baseball: it is more about noticing how their smartphone screen automatically transitions from portrait to landscape mode. Indeed, smartphone behaviours of this type are the starting point for the kind of digital-transition project we will be describing in this paper.

\section{Transformation of Content vs. Transformation of content Delivery}

The digital revolution has produced a vast array of information-technology (IT) tools that are transforming the way we communicate with and deliver content to students, independent of the subject matter. This type of transformation has been and will continue to be widely discussed in the education-research literature (Blazer, 2008; Fies \& Marshall, 2006; Schindler et al., 2017) but is independent of the digital transition we discuss here: The former transformation changes the manner in which content is delivered, whereas the latter involves a change in the content itself. The former involves adapting and then using tools made possible by technology; the latter, as we shall presently explain, incorporates into the curriculum an understanding of digital technology itself and its associated data-processing paradigms.

\section{Classical Physics Meets the Digital World}

A major impediment to the latter transformation is the fact that curriculum content is, to borrow a term from game theory, a zero-sum game: If we add new content related to digital technologies, we usually have to remove some traditional content to make room for it. The strategy is to conceive of examples of digital-world behaviours that illustrate traditional scientific concepts. In this manner, we keep the traditional content intact, replacing only traditional examples with digital-era ones.

Our challenge, then, is to find, within the ideas and concepts of digital technology, examples that illustrate classical physics concepts. The project in our case study does exactly that by carefully designing activities in which students examine modern smartphone behaviours that illustrate fundamental physical principles.

The general potential for smartphones to enhance the classroom experience has been discussed widely (Buck et al., 2013; Langan et al., 2016; Park et al., 2012), including in the present journal (Mammadova, 2018). This has been investigated for some time within the physics education research community: earlier attempts examined handheld devices, such as the Nintendo Wiimote (Hochberg et al., 2016), with the much more versatile smartphone devices (Arribas et al., 2015; Monteiro \& Martí, 2016; Tornaría et al., 2014; Vieyra et al., 2015), including tablets (Egri \& Szabó, 2015), quickly becoming of greater interest. 
The project we will discuss here builds on these initiatives and has itself been described in various international journals (Hinrichsen \& Larnder, 2018; Larnder, 2019a, 2019b; Larnder \& Larade, 2019). It has also been extensively promoted locally (Larnder, 2018a, 2018b; Larnder \& Portelance, 2018, 2019a, 2019b), and in some cases (Larnder, 2019c; Moon, 2018), has been published in both official languages. It provides a series of laboratory activities that rely on the accelerometer motion sensors found in current-generation smartphones. An additional digital-era component is found in the laboratory apparatus used for each activity, since they are built using 3D-print technology.

\section{Quebec's Digital Action Plan}

The Quebec government has long recognized the need for stimulating and supporting systemic change in its educational system. At the college level specifically, it administers a number of programs ${ }^{1}$ which have been increasingly geared towards digital literacy. Our case study, for example, is in its 4 th year of funding under such programs.

The Quebec government recently deployed its Digital Action Plan (MESS, 2018), an ambitious multi-year project for carrying out a digital transition across the entire Quebec educational system. It recognizes three broad categories of activities and investments, as listed in Table 1.

\section{Table 1}

High-level orientations of the Digital Action Plan

\begin{tabular}{cl}
\hline Orientation & Description \\
\hline 1 & Support the development of the digital skills of young people and adults \\
2 & Make use of digital technologies to enhance teaching and learning practices \\
3 & Create an environment conducive to the development of digital technologies \\
\hline
\end{tabular}

The framework as a whole is quite comprehensive. Indeed, it can for this reason serve as a checklist even for stakeholders evaluating projects that are not directly funded by it, such as the one we describe here. The last orientation in the table, which accounts for a large portion of the budget, pertains to infrastructure investments, some of which, as we shall explain below, would be particularly effective in achieving the digital-technology development goals of the project that we shall be examining here.

\section{Digital-Era Laboratory Activities}

In our case study, the project's initial goals were to develop a new set of laboratory activities involving devices and phenomena that are specific to the digital age. Such activities have to meet the condition that they reinforce student learning and integration of the classical physics principles identified in the existing college-level physics curriculum. Trials would be carried out with individual students iteratively until the activities were considered ready to be pursued in a full-classroom setting.

1. Programme de recherche et d'experimentation pédagogiques (PREP); Programme d'aide à la recherche sur l'enseignement et l'apprentissage ( PAREA ); Canada-Québec Agreement on Minority Language Education and Second-Languages Instruction (ECQ); College researcher program of the Fonds de Recherche du Québec (FRQNT); Persévérance et réussite en sciences à l'enseignement supérieur (PRPRS). 


\section{Accelerometers and Smartphones}

Accelerometer sensors were quickly identified as a promising category of device for students to explore. The concept of acceleration is ubiquitous in physics, but students often have difficulty with it, and most laboratory activities only obtain acceleration values by performing calculations using data related to the position of objects. Accelerometers are devices that can measure accelerations directly, potentially making the concept of acceleration more accessible to students. They are widely used for mobile motion sensing, including smartphones, sleep-monitoring and fitness-monitoring devices.

Recent advances in micro-electromechanical (MEMS) sensors (Gardner et al., 2001, chap. 8) have made these devices small, inexpensive and accurate enough to produce reliable results. A wide variety of stand-alone accelerometer devices were acquired and tested for reliability, configuration options and workflow usability.

Smartphones also host accelerometer sensors, and an increasing number of apps available enable students to view and collect the data from them. By the end of the first year of trials, it was clear that smartphone apps on both Android and iOS platforms were reliable and supported a simple data workflow. Smartphones quickly became the device of choice for laboratory activities. An additional element of student engagement was gained through the pride and fascination students experienced in using their very own familiar smartphone devices for an entirely new purpose.

\section{Portrait-Landscape Transitions}

The first promising activity involved an examination of the familiar portrait-landscape transition that automatically occurs when changing the orientation of a smartphone. This takes place typically when using photo-viewing or texting apps. Students are instructed to carefully measure the critical angle at which this transition takes place, and to interpret the corresponding output of the actual accelerometer sensor used by the smartphone to track such orientations. By examining the accelerometer data, students deduce the critical angle that they had originally measured by other means.

The activity is a digital-age replacement for the classical example widely known as "the inclined plane." The same fundamental physics concept is covered: the decomposition of the gravitational vector into components along the axes of an inclined frame of reference-in this case, the frame of reference of the smartphone. Additional skills include understanding the difference between global and local coordinate systems, and the determination of the angle of a component-form vector as summarized in Table 2.

Table 2

Properties of two sample lab activities

\begin{tabular}{|c|c|c|c|}
\hline Title & Classical concept & Competencies & $\begin{array}{l}\text { 3D-printed } \\
\text { apparatus }\end{array}$ \\
\hline $\begin{array}{l}\text { Investigation of the } \\
\text { inclined plane using } \\
\text { smartphones and the } \\
\text { TiltTray }\end{array}$ & the inclined plane & $\begin{array}{l}\text { gravity; } \\
\text { normal forces; } \\
\text { vectors; } \\
\text { local and global coordinate systems; } \\
\text { data processing; }\end{array}$ & the "TiltTray" \\
\hline $\begin{array}{l}\text { Rotational motion using } \\
\text { smartphones and the } \\
\text { SpinFrame }\end{array}$ & centripetal acceleration & $\begin{array}{l}\text { vectors; } \\
\text { centripetal acceleration; } \\
\text { local and global coordinate systems; } \\
\text { data processing; }\end{array}$ & the "SpinFrame" \\
\hline
\end{tabular}




\section{Spinning Smartphones}

A second successful laboratory activity involved spinning students' smartphones and examining the resulting acceleration output. Student engagement was elicited, this time, by the vague sense of danger produced in seeing their beloved phones spinning quickly. The accelerometer output, in this case, demonstrates the principle of centripetal acceleration, a quantity that exists even when an object is rotating at a uniform rate.

A particular insight arises in the students when they are able to conclude that, regardless of where they place the phone on the rotating surface, the acceleration vector always points towards the center of rotation. In addition, they can carry out some bona fide digital-era reverse engineering: By putting together the results achieved when the phone is placed in several different positions, they are able to deduce the exact location of the accelerometer sensor within the body of the phone. They can then obtain circuit diagrams of their own smartphone model to obtain visual confirmation of the result they obtained.

For the portrait-landscape experiment, an apparatus dubbed the "TiltTray" was developed; a set is depicted in Figure 1. It holds smartphones of a variety of shapes on an inclined place that can be set to any desired angle. It has a built-in protractor for accurate direct measurement of the angle of incline.

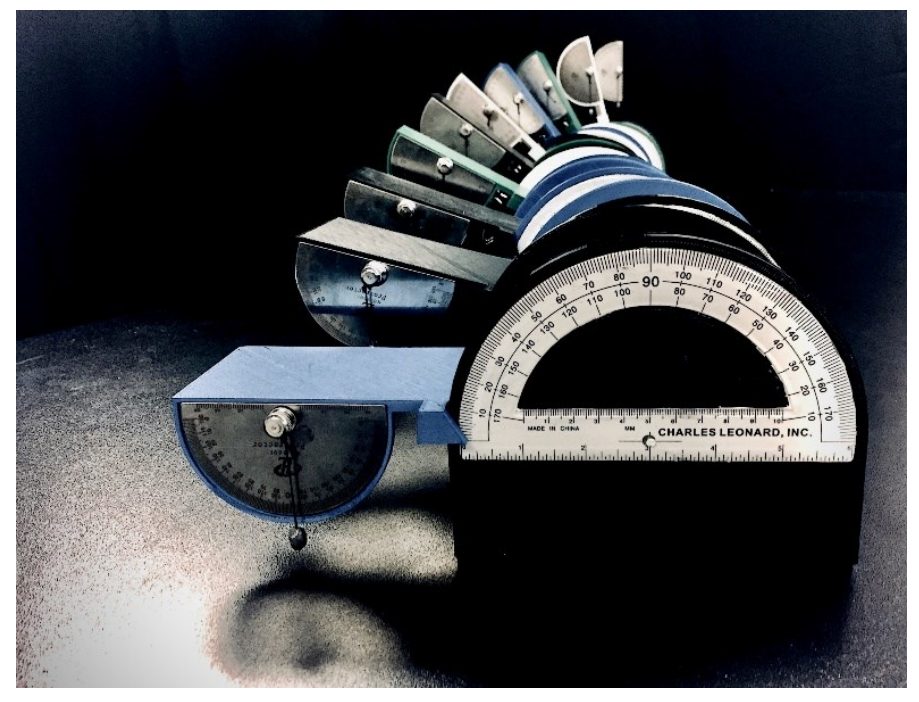

\section{Figure 1}

A 3D-printed TiltTray apparatus set

For the spinning smartphone, another apparatus was developed. Dubbed the "SpinFrame", it consists of an 8-1/2-by-11-inch rectangular frame that perfectly admits a standard piece of paper, and on top of which is placed the smartphone. The frame prevents the phone from slipping off the rotating surface and provides reference positions to measure from. The frame sits on top of a record player adapted to the purpose.

Both of these apparatuses are in fact "mixed-media" objects: The TiltTray requires a conventional protractor to be glued into place on the 3D-printed surface; The SpinFrame has a motorized base that is bought off-the-shelf in the form of an inexpensive record player. One of the consequences is that some assembly is required, and therefore, parts, materials and assembly instructions need to be documented. 


\section{Project Evolution}

\section{The Technology-Adoption Process}

Each lab activity is refined in an iterative manner by running pilot projects with individual students and adjusting the written lab instructions accordingly. Additional iterations take place with full classrooms of students, at which point the activity is made available to other teachers for adoption. The first early adopters were the project initiators' colleagues within the same Physics department. The next ones were teachers in the Engineering Technologies program of the same college.

As the instructions became more advanced, they began to be made available to teachers at other colleges for extramural adoption. As usage grew, variations and improvements on the original lab activity occurred. These became new resources to share within the network of participating colleges, contributing to the overall collective benefit. Table 3 summarizes the historical usage to date of the two sample labs described above.

Table 3

Usage history of lab activities

\begin{tabular}{|c|c|c|c|c|c|c|}
\hline Year & Semester & Lab activity & Department & College & \# classes & \# students \\
\hline \multirow[t]{2}{*}{2017} & Fall & TiltTray & Physics & John Abbott & 0 & 4 \\
\hline & & TiltTray & Physics & John Abbott & 1 & 40 \\
\hline \multirow[t]{4}{*}{2018} & Winter & SpinFrame & Physics & John Abbott & 0 & 3 \\
\hline & & TiltTray & Physics & John Abbott & 4 & 160 \\
\hline & & SpinFrame & Engineering Technologies & John Abbott & 1 & 25 \\
\hline & & TiltTray & Engineering Technologies & John Abbott & 1 & 25 \\
\hline \multirow[t]{7}{*}{2018} & Fall & SpinFrame & Physics & John Abbott & 0 & 1 \\
\hline & & SpinFrame & Physics & John Abbott & 4 & 160 \\
\hline & & SpinFrame & Physics & Marianopolis & 0 & 1 \\
\hline & & SpinFrame & Physics & Marianopolis & 1 & 30 \\
\hline & & TiltTray & Physics & John Abbott & 0 & 1 \\
\hline & & TiltTray & Physics & Marianopolis & 1 & 30 \\
\hline & & TiltTray & Physics & John Abbott & 7 & 280 \\
\hline \multirow[t]{5}{*}{2019} & Winter & SpinFrame & Physics & Marianopolis & 11 & 330 \\
\hline & & SpinFrame & Engineering Technologies & John Abbott & 1 & 25 \\
\hline & & TiltTray & Engineering Technologies & John Abbott & 1 & 25 \\
\hline & & TiltTray & Physics & Marianopolis & 3 & 90 \\
\hline & & TIltTray & Physics & John Abbott & 4 & 160 \\
\hline \multirow[t]{4}{*}{2019} & Fall & SpinFrame & Industrial design* & Vieux Montréal & 1 & $15^{*}$ \\
\hline & & TiltTray & Physics & John Abbott & 4 & 160 \\
\hline & & SpinFrame & Physics & Marianopolis & 8 & 240 \\
\hline & & SpinFrame & Physics & John Abbott & 4 & 160 \\
\hline \multirow[t]{3}{*}{2020} & Winter & SpinFrame & Engineering Technologies & John Abbott & 1 & 25 \\
\hline & & TiltTray & Engineering Technologies & John Abbott & 1 & 25 \\
\hline & & TiltTray & Physics & John Abbott & 1 & 40 \\
\hline
\end{tabular}




\begin{tabular}{clllllc}
\hline Year & Semester & Lab activity & Department & College & \# classes & \# students \\
\hline 2020 & Winter & TiltTray & Natural sciences* & Vieux Montréal & 2 & 41 \\
& (cont.) & SpinFrame & Natural sciences* & Vieux Montréal & 2 & 41 \\
& & TiltTray & Mechanical Engineering & Vieux Montréal & 1 & $17 *$ \\
& & SpinFrame & Mechanical Engineering & Vieux Montréal & 1 & $17 *$ \\
& & SpinFrame & Physics & Marianopolis & 11 & $340^{* *}$ \\
\hline & & & Totals & $\mathbf{7 7}$ & $\mathbf{2 1 7 1 *}$
\end{tabular}

* A previous version of this table, available online until mid-October 2020, displayed an erroneous value.

** This last usage item was cancelled due to the COVID-19 pandemic. It is excluded from the grand total.

\section{Enlarging the Repertoire of Lab Activities}

The two activities described above cover the classical topics of inclined planes and circular motion. Additional lab activities continue to be developed using the same digital-era tools. These include experiments involving exploration of oscillations; development of 3D spatial reasoning for the purpose of understanding magnetic phenomena; and identification of hand-drawn alphabet symbols from accelerometer signals.

\section{D-Print Capability in the College Network}

The use of 3D-print technology to design and produce supporting equipment for lab activities opens up an exciting new category of sharing and collaboration among colleges. Adopting colleges can now not only download and print (paper) instructions for lab activities, but also the (3D-printed) equipment that the students will be manipulating during those activities. A freelyavailable resource package contains all the necessary documents described in Table 4.

Table 4

Elements of the open-source educational resource package

\begin{tabular}{ll}
\hline Category & Item \\
\hline Lab activities & Instructions for students \\
& App instructions (installation, usage) \\
& Teacher notes (duration, skills, strategies) \\
& Presentation material for accelerometers \\
\hline 3D-printable equipment & 3D-modeling source files \\
& Universal 3D format files (STL) \\
& 3D-printing guide \\
& Construction guide (parts, materials, assembly instructions) \\
\hline
\end{tabular}

Such a forward-looking vision was made possible only because of the technological lead of the college ${ }^{2}$ hosting the project: It had already invested in a dozen 3D printers for its Engineering Technologies program, including a large-volume printer; and had acquired the valuable skills of lab technicians in calibrating and maintaining the equipment and in assisting students and faculty members in their use.

2. John Abbott College, Sainte-Anne-de-Bellevue, Quebec. 
Indeed, this novel delivery model (paper-printed instructions plus 3D-printed equipment) assumes a certain level of 3D-print capability in adopting colleges, which involves both investing in 3D-print equipment and in training staff to operate it effectively. Such capability is only beginning to emerge within the college network. Four years into the project, all equipment is still being produced using the 3D-print farm at the hosting college and lent on a temporary basis to the external early-adoption colleges. Initial 3D-print trials have taken place at three other colleges $^{3}$ in the network, but none are yet at the capability level of producing a full-classroom set for their exclusive internal use.

\section{Discussion}

\section{Infrastructure Investments: A Symbiotic Relationship}

As discussed previously, the advancement of the 3D-print component of the project, and thus of the project as a whole, depends on the degree of 3D-print capability within the college network. Although no systematic evaluation of this capability has been undertaken, current project experience suggests that it has been generally lacking; and that, in this sense, the project appears to be lamentably ahead of its time.

With the recent deployment of the Digital Action Plan, however, the situation looks altogether different. Section 3 of the Plan (see Table 1), representing the bulk of the funding, concerns network-wide investments in infrastructure, wisely combined with a freedom granted to individual institutions in making strategic choices in equipment purchases. One of the potential areas of investment for colleges lies in building up their 3D-print capability.

This has the potential of producing a valuable symbiotic relationship. For the project at hand, it reduces the barrier to adopting the lab activities: It becomes attractive and inexpensive when both lab instructions and lab equipment can be printed locally. For the architects behind the Digital Action Plan, it ensures investment choices that contribute to visible and world-class uses of technology in a classroom setting, all the while ensuring equal accessibility for even the most remote 3D-print-capable locations within its geographical territory.

From the point of view of college administrators, the project is a rare but welcome example of some of their infrastructure investment being used for a purpose that is both tangible and visible: There is a concrete image of their own locally-printed laboratory equipment being used for the benefit of engaged students learning physics through the use of their own smartphone sensors.

\section{D-Print Capability: New Skills for Teachers and Support Staff}

3D-print capability involves much more than just the acquisition of equipment. Both teachers and support staff need to develop skills in using 3D modeling software in order to specify the shapes to be printed, and become familiar with the workflow from 3D modeling file formats to the final printed object. A key element is training support staff in the calibration and maintenance of the equipment, as well as in the management of the various print requests and of the supply of 3D filament.

Administrators need to ensure that their investment can benefit a large number of stakeholders effectively; and, hopefully, find ways to foster collaborations among departments and among categories of employees. Indeed, in our case study, three of the currently-participating colleges

3. Marianopolis College (Physics), CÉGEP du Vieux Montréal (Industrial Design) and Dawson College (Physics). 
have teachers working closely with lab technicians in the development of their 3D-print capability. The project has also stimulated significant collaborations between the departments of Physics and Engineering Technologies at one college ${ }^{4}$, and between the departments of Physics and Industrial Design in another. ${ }^{5}$

The project, therefore, can serve i) as a stimulus for adapting and integrating personnel into the new workflow implied by 3D-print technology; ii) as a concrete example of a comprehensive 3D-print project that is purposeful and pedagogically oriented; and iii) as a model and creative stimulant for future projects within such educational institutions.

\section{The Digital Action Plan: A Reference Framework}

This case study presents us with an interesting situation in which one type of innovation ( 3Dprinted equipment ) is co-developed in support of another innovation (lab activities using smartphone sensors). Although there are significant interactions between their parallel and interdependent development, they nevertheless follow two broad phases characteristic of most educational-innovation projects.

In the establishment phase, projects begin with ideas and sketches; are elaborated as prototypes; are iteratively tested and improved, first through pilot programs with individual students, and later with individual teachers in a classroom setting. In the elaboration phase, they are shared with more practitioners, usually in the same department or college as the project initiator. An important milestone is the adoption of the innovation by practitioners outside of the initiating college. The extramural adoptions (see Table 3), in turn, bear witness to the value of the innovations, and signal a level of project maturity in which a plan for broader deployment within the college network can be considered.

Each developmental phase involves new priorities for the further development of the project. In the first phase, the emphasis is in providing teachers with the resources needed for carrying out the laboratory activity itself. In the second phase, one obstacle to further elaboration is the need to support the development of 3D-print skills in teachers and support staff. These two concerns correspond to the two categories of resources identified in Table 4. In the broader deployment phase, this bottleneck lies, as discussed, in the availability of 3D-print equipment in the adopting colleges.

It is instructive to interpret these development challenges in terms of the framework provided by the aforementioned Digital Action Plan. Indeed, as summarized in Table 5, it is clear that the Plan is comprehensive enough to account for all the categories of support identified in this Discussion.

4. John Abbott College.

5. CÉGEP du Vieux Montréal. 


\section{Table 5}

Sections of the Digital Action Plan relevant to the case studys

\begin{tabular}{|c|c|c|c|c|c|}
\hline \multirow[t]{2}{*}{ General topic } & \multirow[t]{2}{*}{ Specific measure } & \multicolumn{4}{|c|}{ Reference } \\
\hline & & $\begin{array}{l}\text { Orienta- } \\
\text { tion }\end{array}$ & $\begin{array}{l}\text { Area of } \\
\text { inter- } \\
\text { vention }\end{array}$ & Objective & Measure \\
\hline \multirow[t]{3}{*}{$\begin{array}{l}\text { Pedagogical project } \\
\text { development }\end{array}$} & $\begin{array}{l}\text { Promote innovative pedagogical practices and the } \\
\text { potential of digital technologies in education }\end{array}$ & 1 & 2 & 1.3 & 08 \\
\hline & $\begin{array}{l}\text { Support the acquisition and development of } \\
\text { digital educational resources }\end{array}$ & 2 & 3 & 2.1 & 11 \\
\hline & $\begin{array}{l}\text { Encourage innovative projects involving digital } \\
\text { technologies }\end{array}$ & 2 & 3 & 2.1 & 12 \\
\hline $\begin{array}{l}\text { Acquisition of } \\
\text { equipment }\end{array}$ & $\begin{array}{l}\text { Support educational institutions in their } \\
\text { acquisition of digital equipment for pedagogical } \\
\text { purposes }\end{array}$ & 3 & 8 & 3.3 & 29 \\
\hline \multirow[t]{4}{*}{$\begin{array}{l}\text { Development of } \\
\text { skills in teachers } \\
\text { and support staff }\end{array}$} & $\begin{array}{l}\text { Develop a new competency framework for the } \\
\text { teaching profession to foster the integration of } \\
\text { digital }\end{array}$ & 1 & 2 & 1.2 & 4 \\
\hline & $\begin{array}{l}\text { technologies into the educational practices of } \\
\text { future teachers }\end{array}$ & & & & \\
\hline & $\begin{array}{l}\text { Foster the continuing education of teachers, non- } \\
\text { teaching professionals and support staff in digital } \\
\text { pedagogy }\end{array}$ & 1 & 2 & 1.2 & 5 \\
\hline & $\begin{array}{l}\text { Offer technical support in educational institutions } \\
\text { to help learners and staff use digital devices for } \\
\text { pedagogical purposes }\end{array}$ & 3 & 8 & 3.3 & 31 \\
\hline
\end{tabular}

\section{A Promising Spinoff: Al Sensor Research}

Small low-cost MEMS accelerometer sensors are still a relatively new technology. After four years, projects have resulted in many explorations of their use in the analysis of a wide variety of motions. Only a small subset of those opportunities have been selected as appropriate for introducing fundamental physics concepts at the college level.

The accumulation of more advanced motion-analysis ideas has resulted in a new spinoff project (Larnder, 2019d) that defines a promising new area of fundamental research. It involves machine-learning techniques for interpreting accelerometer data and is funded independently of the present project (Fonds de recherche Nature et technologies, n.d.). It benefits students not in a classroom setting but rather through their individual participation in research tasks. Some additional contributions to digital-era pedagogy are likely to arise from it, in the form of educational activities involving computational techniques and the use of machine-learning frameworks (Larnder, 2020).

\section{Conclusion}

The twin challenges of innovation in the educational sector are accessibility and longevity. If a new approach requires too many resources to implement or acquire, then it is effectively 
inaccessible, and will not be adopted very widely. At the same time, if it cannot evolve along with its community of users, then it will eventually die out, in the "survival-of-the-fittest" sense. The educational innovation at stake in our case study is, of course, the set of smartphone-based physics experiments; and the most promising response to the twin challenges is, as discussed, the full exploitation of 3D-print technology.

The Quebec ministry of education has recognized the importance of these challenges through its direct support of both the innovation itself ${ }^{6}$ and its safeguarding mechanism ${ }^{7}$ (MEES 2020). The recent deployment of its broad Digital Action Plan (MEES, 2018) is expected to bring additional indirect benefits to the project at a time when it is just about to be more broadly adopted within the college network. Such synergies are the direct result of both the comprehensiveness of the Plan's framework and its emphasis on a flexible and collaborative governance that grants considerable autonomy to individual colleges in responding to opportunities as they emerge.

Our case study demonstrates the potential for 3D-print technology as a tool of empowerment for the college community as whole, and in particular for students and teachers who are allowed a certain degree of control in creating the apparatus that best contributes to their learning. Opensource licensing encourages a healthy culture of collaboration and innovation that the entire college network can benefit from; and the project as a whole can serve as a model to inspire similar innovations at the high school and university levels.

Regarding digital-transition initiatives, it is in the education of science students in particular that we face a double challenge: We require a transition not only in the learning and communication tools that are used to present the curriculum material, but also in the transformation of the curriculum content itself. This latter transformation is vital if we want to prepare these students to face the challenges of tomorrow's world, in which they are not only users of technology, but also scientists who understand how such technologies work and who are therefore capable of designing new innovations.

\section{Acknowledgements}

This work was funded by a grant from the Canada-Québec Agreement on Minority Language Education and Second-Languages Instruction.

\section{References}

Alvermann, D. E. (2004). Media, information communication technologies, and youth literacies: A cultural studies perspective. American Behavioral Scientist, 48(1), 78-83. https://doi.org/10.1177/0002764204267271

Arribas, E., Escobar, I., Suarez, C. P., Najera, A., \& Beléndez, A. (2015). Measurement of the magnetic field of small magnets with a smartphone: A very economical laboratory practice for introductory physics courses. European Journal of Physics, 36(6), Article 065002. https://doi.org/10.1088/0143-0807/36/6/065002

6. Research project "Physics laboratories with mobile accelerometers" funded by the Canada-Québec Agreement on Minority Language Education and Second-Languages Instruction.

7. Research projects "Physics laboratories shared via 3D print technology [Laboratoires de physique partagés par le biais d'impression 3D]" and "Elaboration of a physics laboratory project using mobile accelerometers [Élaboration d'un projet de laboratoires de physique avec accéléromètres mobiles]" both funded by the CanadaQuébec Agreement on Minority Language Education and Second-Languages Instruction. 
Blazer, C. (2008). Literature review: Educational technology (ED536868). ERIC. https://eric.ed.gov/?id=536868

Buck, J. L., McInnis, E., \& Randolph, C. (2013). The new frontier of education: The impact of smartphone technology in the classroom. In Proceedings of the 2013 ASEE Southeast Section Conference. http://se.asee.org/...

Crompton, H., Burke, D., Gregory, K. H., \& Gräbe, C. (2016). The use of mobile learning in science: A systematic review. Journal of Science Education and Technology, 25(2), 149-160. https://doi.org/10.1007/s10956-015-9597-x

Egri, S., \& Szabó, L. (2015).. Analyzing oscillations of a rolling cart using smartphones and tablets. The Physics Teacher, 53(3), 162-164. https://doi.org/10.1119/1.4908086

Fies, C., \& Marshall, J. (2006). Classroom response systems: A review of the literature. Journal of Science Education and Technology, 15(1), 101-109. https://doi.org/10.1007/s10956006-0360-1

Fonds de recherche Nature et technologies. (n.d.). Inférence de mouvements contraints à partir d'un signal d'accéléromètre - Christopher Isaac Larnder. Résumé du projet

[Accelerometry-based inference of constrained motions - Christopher Isaac Larnder. Project summary]. Government du Québec. http://frqnt.gouv.qc.ca/...

Gardner, J. W., Varadan, V. K., \& Awadelkarim, O. O. (2001). Microsensors, MEMS, and smart devices. John Wiley \& Sons. https://doi.org/10.1002/9780470846087

Hinrichsen, P. F., \& Larnder, C. I. (2018). Combined viscous and dry friction damping of oscillatory motion. American Journal of Physics, 86(8), 577-584.

https://doi.org/10.1119/1.5034345

Hochberg, K., Kuhn, J. et Müller, A. (2016). Science education with handheld devices: A comparison of Nintendo WiiMote and iPod touch for kinematics learning. Perspectives in Science, 10, 13-18. https://doi.org/10.1016/j.pisc.2016.01.008

Langan, D., Schott, N., Wykes, T., Szeto, J., Kolpin, S., Lopez, C., \& Smith, N. (2016). Students' use of personal technologies in the university classroom: Analysing the perceptions of the digital generation. Technology, Pedagogy and Education, 25(1), 101-117. https://doi.org/10.1080/1475939X.2015.1120684

Larnder, C. I. (2018a, May). Using smartphone tilt behaviours to teach physics [Paper presentation]. Annual Conference of Supporting Active Learning and Technological Innovation in Science Education (SALTISE), Montréal, Québec, Canada.

Larnder, C. I. (2018b, October). Activités de physique avec accéléromètres mobiles [Paper presentation]. Annual Conference of the Association pour l'enseignement de la science et technologie du Québec (AESTQ), Sorel-Tracy, Québec, Canada.

Larnder, C. I. (2019a). A purely geometrical method of locating a smartphone accelerometer. The Physics Teacher, 58(1), 52-54. https://doi.org/10.1119/1.5141974

Larnder, C. I. (2019b). Acceleration discontinuities in dry-friction oscillations. American Journal of Physics, 87(10), 784. https://doi.org/10.1119/1.5123455

Larnder, C. I. (2019c, January 28). 3D-print technology for smartphone-based physics experiments. Profweb. http://profweb.ca/... 
Larnder, C. I. (2019d, May). Accelerometry-based inference of constrained motions [Poster presentation]. Physics and AI Workshop, Montréal, Canada.

http://www.physics.mcgill.ca/ai2019/booklet.pdf

Larnder, C. I. (2020, May). Enseigner les sciences dans un cadre d'apprentissage automatique [Paper presentation]. $7^{\mathrm{e}}$ colloque international en Éducation. enjeux actuels et futurs de la formation et de la profession enseignante, Montréal, Canada. https://colloque2020.crifpe.ca/fr/papers/details/704

Larnder, C. I., \& Larade, B. (2019). On the determination of accelerometer positions within host devices. American Journal of Physics, 87(2), 130-135. https://doi.org/10.1119/1.5082536

Larnder, C. I., \& Portelance, E. (2018, August). Activités de physique avec accéléromètres mobiles [Paper presentation]. Colloque sur l'enseignement de la science et de la technologie au collégial, Association pour l'enseignement de la science et de la technologie du Québec (AESTQ), Sorel-Tracy, Québec, Canada.

Larnder, C. I., \& Portelance, E. (2019a, January 30). Impression $3 D$ : quel potentiel pour les laboratoires de physique? [Video]. Webinar held by the Association pour les applications pédagogiques de l'ordinateur au postsecondaire (APOP). https://apop.qc.ca/...

Larnder, C. I., \& Portelance, E. (2019b, May). La fabrication additive distribuée au service de l'éducation scientifique : l'étude de cas des laboratoires de physique basés sur l'utilisation des téléphones intelligents [Conference presentation abstract]. Colloque 603 - Enjeux globaux et locaux de l'innovation technologique et sociale : réalités et potentiels des Living Labs, Fab Labs et labos citoyens. Annual conference of the Association francophone pour le savoir (ACFAS), Ottawa, Canada. http://acfas.ca/...

Mammadova, T. (2018). Smartphones and their role in the modern classroom. International Journal of Technologies in Higher Education, 15(2), 5-14.

https://doi.org/10.18162/ritpu-2018-v15n2-01

Ministère de l'Éducation et de 1'Enseignement supérieur. (2018). Digital action plan for education and higher education - Students: At the heart of the digital revolution [Plan d'action numérique en éducation et en enseignement supérieur. Les élèves et les étudiants : au cœur de la révolution numérique]. Gouvernement du Québec. http://education.gouv.qc.ca/...

Ministère de l'Éducation et de l'Enseignement supérieur. (2020). Entente Canada-Québec. Projets soutenus financièrement. Gouvernement du Québec. http://education.gouv.qc.ca/...

Monteiro, M., \& Martí, A. C. (2016). Using smartphone pressure sensors to measure vertical velocities of elevators, stairways, and drones. Physics Education, 52(1), Article 015010. https://doi.org/10.1088/1361-6552/52/1/015010

Moon, R. W. (2018, August 28). Accelerated learning with smartphones in physics. Profweb. https://profweb.ca/...

Morley, D. (2001). Belongings: Place, space and identity in a mediated world. European Journal of Cultural Studies, 4(4), 425-448. https://doi.org/10.1177/136754940100400404 
Park, S. Y., Nam, M.-W., \& Cha, S.-B. (2012). University students' behavioral intention to use mobile learning: Evaluating the technology acceptance model. British Journal of Educational Technology, 43(4), 592-605. https://doi.org/10.1111/j.14678535.2011.01229.x

Schindler, L. A., Burkholder, G. J., Morad, O. A., \& Marsh, C. (2017). Computer-based technology and student engagement: A critical review of the literature. International Journal of Educational Technology in Higher Education, 14(1), Article 25. https://doi.org/10.1186/s41239-017-0063-0

Strimel, G., \& Grubbs, M. E. (2016). Positioning technology and engineering education as a key force in STEM education. Journal of Technology Education, 27(2), 21-36. https://doi.org/10.21061/jte.v27i2.a.1

Tang, K.-Y., \& Tsai, C.-C. (2016). The intellectual structure of research on educational technology in science education (ETiSE): A co-citation network analysis of publications in selected journals (2008-2013). Journal of Science Education and Technology, 25(2), 327-344. https://doi.org/10.1007/s10956-015-9596-y

Tornaría, F., Monteiro, M., \& Marti, A. C. (2014). Understanding coffee spills using a smartphone. The Physics Teacher, 52(8), 502-503. https://doi.org/10.1119/1.4897595

Vieyra, R., Vieyra, C., Jeanjacquot, P., Marti, A., \& Monteiro, M. (2015). Five challenges that use mobile devices to collect and analyze data in physics. The Science Teacher, 82(9), $32-40$.

Weintrop, D., Beheshti, E., Horn, M., Orton, K., Jona, K., Trouille, L., \& Wilensky, U. (2016). Defining computational thinking for mathematics and science classrooms. Journal of Science Education and Technology, 25(1), 127-147. https://doi.org/10.1007/s10956015-9581-5

Zwicker, A. Bloom, J., Albertson, R. et Gershman, S. (2015). The suitability of 3D printed plastic parts for laboratory use. American Journal of Physics, 83(3), 281-285. https://doi.org/10.1119/1.4900746 